\title{
Empirically Supported Development of Specialisation Courses for Extra-Occupational Studies within the Discipline of Business Informatics
}

\author{
Michael Städler ${ }^{1}$, Knut Linke $^{1} \&$ André von Zobeltitz ${ }^{2}$ \\ ${ }^{1}$ Institute for Knowledge Management, University of Applied Sciences Weserbergland, Hamelin, Germany \\ ${ }^{2}$ Dept. of Business Economics, University of Applied Sciences Weserbergland, Hamelin, Germany \\ Correspondence: Michael Städler, Institute for Knowledge Management, University of Applied Sciences \\ Weserbergland, Am Stockhof 2, D-31789 Hamelin, Germany. Tel: 49-9559-56. E-mail: staedler@ hsw-hameln.de
}

Received: October 17, 2018

doi:10.5539/hes.v8n4p177

\author{
Accepted: November 2, $2018 \quad$ Online Published: November 19, 2018 \\ URL: https://doi.org/10.5539/hes.v8n4p177
}

\begin{abstract}
This article contains the analytical results of qualitative and descriptive research regarding the definition of specialisation courses in the areas of "Informatics" and "Management" for extra-occupational study offers within the discipline of Business Informatics. The subjects were IT specialists with either foundation or advanced Chamber of Commerce (IHK) IT training, who participated as students in the credit transfer courses developed in the "Open IT" research project, or who were interested in participating. The investigative results reveal clearly in certain parts just what the preferences of working IT students are in terms of the scientific specialisation courses on offer, and how student target groups can be actively and effectively integrated into the design process of degree programme curricula.
\end{abstract}

Keywords: business informatics, digitalisation, Virtualisation, study evaluation, IT professionals

\section{Introduction}

In view of the advancing computerisation of working environments, the demands being placed on IT specialists and executives are constantly changing. Universities must take this change into account if they wish to train the workforce and specialists of tomorrow. As part of the research project "Open IT" the University of Applied Sciences Weserbergland (HSW) - in cooperation with the Technical University of Darmstadt - has succeeded in developing and testing three credit-based study programmes for vocationally trained IT specialists.

This article sheds light on how the empirical results from the testing phase can be used as an impulse for the (ongoing) development of study content. This exemplary approach is intended to render an important contribution to the consideration of how students can be meaningfully involved in the planning of study content in the disciplines of Informatics and Business Informatics. The accompanying evaluation of the course of studies made it possible to deliver a more targeted differentiation of the specialisation subjects on offer for the study programmes, and to enable a diversification of the topics for the integration of new study offers. The study structure for the three envisaged study programmes is described in detail by Städler, von Zobeltitz and Linke (2018). The structure of the cerificated study programme "Bachelor in Business Informatics", which is aimed at IT specialists with foundation Chamber of Commerce IT training, encompasses 16 ECTS credits each for compulsory elective subjects in the disciplines of "Informatics" and "Management". In the certificated study programme "Bachelor in IT Business Management", which was conceived as a credit transfer programme for so-called Operative Professionals (Rogalla \& Witt-Schleuer, 2004; DIHK, 2010), the specialisation disciplines are covered and recognised through the respective specialisations included in the further education programme for Operative Professionals. For this target group, six ECTS credits are planned for a compulsory elective subject in the discipline of "Management" as part of the "Master in IT Business Management" that builds on the "Bachelor in IT Business Management".

It is not the university alone that should be responsible for the range of specialisations available for selection. Likewise, students should be able to help shape the compulsory elective subjects on offer. However, not with complete autonomy in view of the fact that, as the participating researchers suspected, students cannot, on the one hand, determine the necessary specialisation content directly. On the other hand, there was the assumption 
that students would not yet be able to identify the topics they need in the future, nor would they be able to define their contents. For the job market, however, it is important to be able to offer suitably trained workers who can fulfil the requirements at hand.

\section{The Growing Demand Stemming From the Labour Market for Academic IT Specialists}

Against a backdrop of lifelong learning, the target group-specific development of personnel is becoming increasingly important, in order to qualify people for specific employment roles in certain businesses. This is related to the societal trends emerging as part of demographic change (Arndt, 2012), digitalisation and technical change in the world of work (Becker \& Häusling, 2012) and the (operational) globalisation of the working world (Speidel, 2012). These trends in particular affect workers in the discipline of information technologies. The need for new, additional skilled workers and specialists in the field of IT continues its growth unabated. The official, government needs-based analyses of the German labour market anticipate an increase of 71,000 to 218,000 new jobs in the area of IT services by 2030 (Albrecht \& Ammermüller, 2016). The increase in demand, in turn, is accompanied by an increase in the number of gainfully employed persons who have a Master's degree or a university degree compared to those with foundation vocational education (Zika, Maier, Hummel \& Helmrich, 2015). Furthermore, and in the context of this change, light is also shed on the general trend taking hold in the labour market of the Federal Republic of Germany: The range of secondary services is growing, while primary services and the production-oriented activities (Pfeiffer \& Kaiser, 2009) are registering a decrease. In this context, it has to be considered that this change will also trigger an additional reduction in basic activities, including in those professional areas where people are employed without any vocational training, as well as a comparable increase in the volume of higher qualified professional activity (Pfeiffer \& Kaiser, 2009). This change is also true, in particular, for people in the IT sector.

The reason for the increased demand for IT specialists is attributable to the digitalisation and/or the progressive networking and computerisation of society and the associated added value (Castells 2001, 2003). In the context of this social change, information technology enables the global organisation of production capital - largely due to the provision of a global information space and IT-standardised services and processes - to ensure the smooth production of both products and services (Boes \& Kämpf, 2011). Especially within the discipline of IT, this global information space facilitates the standardisation of work, especially through employment-related certificationsand the use of IT governance standards such as ITIL or Prince (Pries, 2010). In order to implement this standardisation and streamlining of processes, as well as to facilitate process reorganisation in the information space (Baukrowitz, 2006) and to generate new offers within the discipline of IT, suitable specialists are a necessity. These individuals must have the necessary IT knowledge and skills set (Pfeiffer \& Suphan, 2015) to be able to act as IT specialists in this intangible working environment in the interest of companies. This raises the question for higher education institutions as to how best to identify suitable study content as part of a competitive study model, and which extra-occupational (and thus job-related) study offers may be deemed necessary. The challenge is to deliver an exact requirements analysis, ascertaining which contents must be offered to the students for subsequent application in the world of work. Company representatives may tend to make general statements in this regard, as the practice-oriented research by Capgemini (2015) reveals. 154 CIOs defined the following tasks as the most important tasks of future IT managers: "Increasing the efficiency of IT" (50.6\%), "Cutting the costs of IT" (36.4\%) and "Expanding digitalisation" (34.4\%). Another question was aimed at the barriers to digitalisation. This was answered by 55 CIOs. $56.4 \%$ of respondents identify the idea "that employees possess too few expertise" as a challenge. In addition, $45.5 \%$ complained that "no overarching planning" exists within the company. These are very vague statements when viewed on balance. There is no differentiation in terms of the occupational profiles permitted under the dual vocational training programme in Germany, or a consideration of the various disciplines of study in IT. For this reason, it is necessary to close this knowledge gap in order to specifically evaluate suitable specialisations for IT employees with Chamber of Commerce (IHK) vocational training.

\section{Methodical Approach}

As part of the research project, students and employers were asked in advance of the survey presented here regarding their substantive expectations for a future-proof, extra-occupational study programme for IT specialists with Chamber of Commerce vocational training. The ideas voiced there were, in part, more general in nature and coincided with the more holistic statements and tendencies previously mentioned in the theory. Requests for definitive specialisations were not made.

The previous surveys showed that employers' requirements mostly stem from the basics of Business Administration, Project Management and the transfer of social and cooperative skills. These special requirements 
placed on the social skills of study participants were taken into account in the preparation of the general curricula for the target groups. Upon the commencement of studies, it was revealed that the (special) target group of experienced IT professionals (von Zobeltitz \& Linke, 2018) needed to be taught these social and cooperative skills at a very early stage of their studies. This goal was realised through a revision of the study programme on offer for the first semesters (Bönick, Huck \& von Zobeltitz, 2018). In principle, most of the desires and suggestions mentioned as well as the occupational requirements cited, related to general course contents.

In a survey that specifically enquired about the desired specialisations and focuses of a study programme, companies occasionally ( 4 out of 31 companies surveyed, 12.9\%) expressed the desire for software engineering and for the offer of a certificated programme in the discipline of IT Infrastructure Libary (3 out of 31 companies, 9.7\%). The small proportion made it difficult to define specialisations or specific study programme offers. It was not possible to deduce the specialisation course contents from the statements provided by the companies. In addition, a further investigation - in this case among prospective IT professionals - showed that the target group of employees has special requirements: This target group does not aim to acquire a general profile for a successful start to their prospective career by gravitating to a particular specialisation, but would rather continue their development in a practice-relevant and scientific way.

For these reasons, students' ideas and requirements should be taken into account on the basis of the descriptive studies carried out. The goal was to gather impulses as to which requirements the working world stipulates, and to what extent these should be taken into account when drafting a study programme offer. The requirements of business and the economy were given due consideration by the university in the preparation of the three study programmes (Städler et al., 2018). In order to survey students' perspective, two groups of students were asked the same questions:

- The group "Business Informatics" (group BI) included students, who have Chamber of Commerce foundation vocational training and who applied for the certificated course "Bachelor in Business Informatics", and who had already begun this in part.

- $\quad$ The group "IT Business Management" (group ITBM) included students, who in the majority of cases were already in possession of Chamber of Commerce foundation vocational training and mandatory advanced vocational training (to attain the title of "Operative Professional"), and who applied for the certificated course "Bachelor in IT Business Management", and who had already begun this in part. For the participants in the certificated study programme "Bachelor in IT Business Management" the possibility exists to take advantage of the offer of the certificated study programme entitled "Master in IT Business Management" following the successful completion of the earlier course.

Detailed information on Chamber of Commerce foundation IT training and related qualifications were published in (Linke, Städler, von Zobeltitz \& Blochberger, 2017).

The investigation consisted of two separate surveys:

In the first survey, BI and ITBM students were interviewed by phone prior to the start of their studies. The students were asked to name up to three specialisation subjects they would like to complete during their studies. In addition, it was ascertained which topics they would consider to be occupationally relevant in the year 2030 . The questions were given a qualitative response by the participants and then evaluated using content text analysis (Mayring, 2015). For this purpose, the frequency and content relatedness of statements were evaluated and the answers to categories (Berger-Grabner, 2016) summarised, based on which the first exemplary suggestions for specialisation subjects were then derived. 
Table 1. Methodical profile

\begin{tabular}{ll}
\hline Survey form & Guideline interview and written online survey \\
\hline $\begin{array}{l}\text { Description of sample } \\
\text { population }\end{array}$ & IT professionals without a degree, but with the desire to undertake further education \\
$\begin{array}{l}\text { Descrion of } \\
\text { Surviewees tool }\end{array}$ & $\begin{array}{l}\text { IT professionals with Chamber of Commerce foundation IT training and/or career } \\
\text { development training as technical experts }\end{array}$ \\
& $\begin{array}{l}\text { First survey: Partially standardised telephone guide interviews } \\
\text { Second survey: Standardised online survey with qualitative and quantitative response } \\
\text { options }\end{array}$ \\
Furvey period & $\begin{array}{l}\text { First survey: Summer semester 2016 } \\
\text { Second survey: Summer semester 2017 }\end{array}$ \\
First survey: 20 IT professionals with Chamber of Commerce foundation IT training \\
and 20 with Chamber of Commerce career development training
\end{tabular}

Overview of the methodical profile of the surveys

After the start of studies, groups BI and ITBM were then re-interviewed. This was managed in the context of an online survey. Here, the students chose examples of specialisation subjects based on scaled questions (Berger-Grabner, 2016). Prior to this, the study programme offer already envisgaged by the university was expanded to include the results of the preliminary investigation. The results of this second survey formed the decision-making basis for the university, as to which specialisation options were to be offered for which study programmes. Fewer students took part in the latter survey, as the total number of students had regeistered a decline after the start of studies due to examinations and the associated results, as well as the amount of extra work attributable to extra-occupational study.

In the second survey, students were also asked to evaluate the specialisation subjects selected by the university. The previous curricula for the two groups already included specially adapted learning content to prepare individuals with prior vocational training for a science-based degree. It was therefore very important for the HSW to develop suitable specialisation programme offers for the respective study groups. It also aims to offer future-proof and targeted professional specialisations. In this context, any proven contents stemming from the experience of those requirements students have of their dual study programmes in terms of practical relevance should also be afforded consideration, in order to ensure a higher degree of practical orientation.

Up to this point, the university had envisaged the following specialisation offers (as of 2016) for the Bachelor group Business Informatics:

- Software engineering: to expand on a candidate's IT knowledge and meet the stated requirements of companies in the disciplines of Software Engineering / Software Development

- Graph theory: to expand on a candidate's knowledge in databases and data storage

- Business Intelligence \& Data Warehouse: to expand on a candidate's knowledge of Data Warehouse and Data Mining

- Finance \& Controlling: To expand on a candidate's foundation knowledge of Controlling for IT professionals as a basis for taking on management tasks at a later date

The following specialisation offers were envisaged (as of 2016) for the group Masters in IT Business Management:

- IT service management: to expand on a candidate's knowledge in the field of IT service management, which based on the university's expectations is an area that many future graduates are anticipated to deal with professionally.

- e-business: Facilitating a foundation understanding of the discipline of e-marketing and digital distribution in the context of e-commerce as a study offer for a suitable professional orientation later on

The various specialisations that should be offered by the university have been specially identified in the following investigations. 


\section{Results of the Investigations}

The results of the surveys involving the BI and ITBM groups are presented below. First of all, those results are presented which stem from the survey of the two groups conducted before the start of studies. All the individuals interviewed here had received a binding offer for their participation in this study programme subsequent to their successful application. This was followed by the survey of those test subjects active in the two pilot study programmes. In both cases, before and during studies, all individuals who were interested in (or who were actually studying) could be interviewed. Individuals who failed to provide any answer in the survey are listed separately.

\subsection{Survey of Group BI and Group ITBM before the Start of Studies}

Before the start of their studies, 20 prospective students were admitted to study for each group. Both groups were equal in size to ensure improved comparability during the accompanying investigations. During the first step, participants were asked which content they would like to see in the specialisation subjects. Each participant could register up to three content-related requests for the specialisation subjects. The groups revealed a host of different preferences.

Table 2. Specialisation subjects - Group BI before the start of studies

\begin{tabular}{lccc}
\hline & \multicolumn{3}{c}{ Group BI (n=20) } \\
\hline Area of specialisation & 1st choice & 2nd choice & 3rd choice \\
\hline Finance / Controlling & 7 & 6 & 2 \\
IT Law / IT Security & 6 & 5 & 4 \\
Software Engineering & 3 & - & 4 \\
Business Management & 2 & 2 & - \\
Business Intelligence \& Data Warehouse & 1 & 4 & 5 \\
No requests & 1 & 1 & 1 \\
Employee Management & - & 1 & 1 \\
Cloud Computing & - & - & 1 \\
Enterprise Resource Planning & - & - & 1 \\
Server / Network Management & - & 1 & 1 \\
\hline Only box "1st choice" was mandatory & \multicolumn{3}{|}{} \\
\hline
\end{tabular}

Among the above-mentioned proposals for specialisation subjects by the group BI, a dominance can be identified in the disciplines of Cost Controlling and IT Law / IT Security.

Table 3. Stated specialisation subjects - Group ITBM before the start of studies

\begin{tabular}{lccc}
\hline & \multicolumn{3}{c}{ Group ITBM (n=20) } \\
\hline Area of specialisation & 1st choice & 2nd choice & 3rd choice \\
\hline Process Optimisation / Process Management & 6 & 3 & 1 \\
Employee Management & 3 & 1 & - \\
Company Management & 3 & 1 & - \\
Business English & 2 & 1 & - \\
Project Management & 2 & 1 & - \\
Mathematics / Statistics & 2 & - & 1 \\
Law (IT / German Civil Code [BGB]) & 1 & - & 2 \\
No requests & 1 & 3 & 9 \\
Business Informatics & - & 3 & 1 \\
IT Security & - & 2 & 2 \\
IT Infrastructure Library (ITIL) & - & 2 & - \\
(Practical) IT solution concepts & - & 1 & 2 \\
(Financial) Controlling & - & 1 & 1 \\
Academic paper & - & 1 & - \\
Business Management & - & - & 1 \\
\hline Only box "1st choice" was mandatory & \multicolumn{3}{c}{} \\
\hline
\end{tabular}

Based on the specialisation requests of the professionally experienced group ITBM, a clear preference in the area of Process and Personnel Management can be identified and thus a direct management orientation. 
The answers submitted by the groups BI and ITBM showed similarities and a relatively clear picture as to what exactly the current expectations of the respective specialisation subjects were. The respective preferences of the different groups were, however, conspicuous. The individuals (ITBM group) in possession of advanced training as "Operative Professionals" were already clearly focusing on topics within the discipline of Management. This is contrasted by those members of the BI group, who only have foundation IT training. This group reveals a focus on operational Controlling tasks and skills (IT Law), which render an operational influence.

Furthermore, participants were asked what future topics they would expect to see in the discipline of IT in the year 2030. It is interesting to note that both groups listed - irrespective of their specialisation requests - the same or similar topics, tendencies and contents, which differ significantly from the desired specialisation subjects.

Table 4. Stated future topics: Group BI and Group ITBM before the start of studies

\begin{tabular}{lcc}
\hline Future topic & Group BI $(\mathrm{n}=20)^{*}$ & Group ITBM (n=20)* \\
\hline Cloud-Computing (Virtualisation) & 13 & 10 \\
Automation, Internet of Things \& Networking & 8 & 8 \\
IT Security & 7 & 9 \\
Virtualisation of Work & 4 & 4 \\
IT Service Management & 4 & - \\
Mobile Solutions & 3 & 2 \\
Social Media & 3 & - \\
Business Intelligence & 2 & - \\
Artificial Intelligence & 2 & - \\
Process Management & 1 & 4 \\
Big Data & - & 6 \\
IT Infrastructure Library (ITIL) & - & 5 \\
Project Management & - & 4 \\
Employee Development / Acquisition & - & 3 \\
Agile Management & - & 2 \\
*Multiple selections possible & & \\
\hline
\end{tabular}

Both groups envisage a future demand on IT in the areas of Cloud Computing, Virtualisation and Automation.

In the ITBM group the aspect of "IT Security" is striking, given that it was frequently mentioned in the survey. It is, however, not a topic that was mentioned in the specialisation subjects, contrary to the responses by the group BI. Overall, the answers to the question of future topics hardly overlap with the desired specialisation subjects.

The topics of "Cloud Computing", "Automation, Internet of Things \& Networking" as well as topics that go hand in hand with the digitalisation of work were dominant in both groups. "Cloud Computing" with its impact on the provision and consumption of IT services on a just-in-time basis, as well as emerging concerns in the context of data security and data protection (Au, 2016), could potentially explain the significant level of interest in "IT security" in part.

\subsection{Survey of Active Students during Their Studies}

On the basis of the above-mentioned future topics and the preferences registered during the first survey, study programmes were then derived for the specialisation discplines of "Informatics" and "Management". A part of the preferences and future topics mentioned did not have to be considered given that these areas - including "Foundations of Business Administration", "Mathematics" or "(Personnel) Management" - already formed part of the standard curricula of various study programmes.

The topics of "Virtualization of work" and "Automation, Internet of Things \& Networking" have been merged into Industry 4.0 / Digital Transformation. Industry 4.0 describes the increasing automation and individualisation of industrial value creation and the horizontal and vertical integration of production steps into the digitalisation production process (Hämmerle, Pokorni \& Berthold, 2018). Thus, Industry 4.0 is the basis for future IT solutions, which are also implemented by IT services in the field of Cloud Computing, and which are executed through the connections of terminals within the framework of the "Internet of Things". In the course of this transformation, we will see increased flexibility in work and organisational structures, as well as a progressive virtualisation of work (Bruckner \& Werter, 2018).

The extracted compulsory elective subjects were subsequently made available to the two target groups for the test selection. During this process, it became apparent that participants were particularly interested in those 
compulsory elective subjects that dealt with the future topics mentioned above. In the BI group, 19 people started the course, all of whom also participated in the survey. In the ITBM group, the number of participants had decreased to 13 by the start of the survey. From both groups, all active students participated in the second survey.

\subsubsection{Results: Group BI}

From the group BI, individuals with foundation vocational IT training revealed quite unique study and elective preferences in part.

Table 5. First and second choice preferences: compulsory elective subject "Informatics"

\begin{tabular}{lcccc}
\hline & \multicolumn{2}{c}{ First choice $(\mathrm{n}=19)$} & \multicolumn{2}{c}{ Second choice $(\mathrm{n}=19)$} \\
Compulsory elective subject & Number & percentile & Number & percentile \\
\hline Cloud-Computing / Virtualisation & 13 & $68.4 \%$ & 2 & $10.5 \%$ \\
Business Intelligence / Data Warehouse* & 3 & $15.8 \%$ & 12 & $63.2 \%$ \\
Software Engineering I \& II* & 3 & $15.8 \%$ & 3 & $15.8 \%$ \\
Graph Theory, Alg. \& Data Structures * & 0 & $0.0 \%$ & 2 & $10.5 \%$ \\
\hline
\end{tabular}

$*$ originally intended by the university as an elective subject

During the test selection in the discipline of Informatics, the group BI showed a preference for a specialisation in "Cloud Computing / Virtualisation", which was only identified as a topic during the preliminary survey.

When considering the previous vocational training of the participants, there were some abnormalities in connection with the choices made. Eight $(61.5 \%)$ of the 13 people who named Cloud Computing and Virtualisation as their first choice were individuals with specialist IT training in System Integration. 75.0\% of these individuals selected "Business Intelligence / Datawarehouse" as a second choice. This was the only training occupation that revealed such a result. Cloud Computing / Virtualisation skills were particularly in demand among IT service providers and public administrations. The group BI also registered a preference for a compulsory elective subject in the field of "Management".

Table 6. First and second choice preferences Compulsory elective subject "Management"

\begin{tabular}{lcccc}
\hline & \multicolumn{3}{c}{ First choice $(\mathrm{n}=19)$} & \multicolumn{2}{c}{ Second choice $(\mathrm{n}=19)$} \\
Compulsory elective subject & Number & percentile & Number & percentile \\
\hline IT Law / IT Security & 12 & $63.2 \%$ & 4 & $21.1 \%$ \\
Industrie 4.0 / Digital Transformation & 7 & $36.8 \%$ & 7 & $36.8 \%$ \\
Finance / Controlling* & 0 & $0.0 \%$ & 8 & $42.1 \%$ \\
\hline * originally intended by the university as an elective subject & \multicolumn{4}{c}{} \\
\hline
\end{tabular}

During the test selection in the discipline of Management, the group BI showed a preference for a specialisation in areas, which were only identified as a topic during the preliminary survey.

Within the discipline of "Management", special features of the occupational group IT specialist for System Integration could also be identified. 66.6\% of IT specialists working in System Integration (six out of nine) chose the specialisation IT Law / IT Security. When electing first and second subjects, there were no correlations between the subjects.

It was noticeable that most people who chose "Industry 4.0 / Digital Transformation" came from larger companies with more than 2,000 employees. The majority of participants who chose IT Law / IT Security work for IT service providers.

Following the test selection, the participants were asked to rate their compulsory elective subjects in the context of their current occupation and in accordance with their level of interest. This task also revealed that those extracted future topics are of particular occupational interest to the study groups. 
Table 7. Interest assessment of all compulsory elective subjects

\begin{tabular}{lcccc}
\hline Compulsory elective subject & Mode $(\mathrm{n}=19)$ & Median $(\mathrm{n}=19)$ & $\mathrm{R}(\mathrm{n}=19)$ & $\mathrm{SD}(\mathrm{n}=19)$ \\
\hline Industrie 4.0 / Digital Transformation & 5 & 4 & $1-5$ & 1.21 \\
Cloud-Computing / Virtualisation & 5 & 4 & $1-5$ & 1.42 \\
IT Law / IT Security & 5 & 4 & $1-5$ & 1.42 \\
Business Intelligence / Data Warehouse* & 4 & 4 & $1-5$ & 1.23 \\
Finance / Controlling* & 3 & 3 & $1-5$ & 0.85 \\
Graph Theory, Alg. \& Data Structures * & 1 & 2 & $1-4$ & 1.17 \\
Software Engineering I \& II* & 1 & 2 & $1-5$ & 1.55 \\
\hline
\end{tabular}

* originally planned as an elective subject

Legend: I find it uninteresting (1), I find it rather uninteresting (2), neither nor (3), I find it rather interesting (4), I find it interesting (5)

When assessing the specialisation topics in terms of interest, those topics with a focus on future requirements revealed the greatest level of interest during the first survey.

The BI and ITBM groups were asked the same questions. However, only subjects from the discipline of "Management" were offered here, given that the discipline of "Informatics" is not intended for this group.

\subsubsection{Results: Group IT Business Management}

The ITBM group, which included IT professionals with both foundation and advanced IT vocational training, also showed a clear preference for the topics extracted in the previous survey.

The offer of "e-Business" was not chosen by any of the participants. Further evaluations revealed no connection between first and second choice. There was also no clear correlation between certain election preferences and sectors, as well as operational vocational training or IT foundation training. It was noticeable that in the first selection the offer of "Industry 4.0 / Digital Transformation" was almost exclusively chosen by individuals from companies with more than 2,000 employees. Furthermore, during the evaluation of interest in the offers a similar preferential bias was determined as with the group BI.

Table 8. First and second choice preferences Compulsory elective subject "Management"

\begin{tabular}{lcccc}
\hline & \multicolumn{3}{c}{ First choice $(\mathrm{n}=13)$} & \multicolumn{2}{c}{ Second choice (n=13) } \\
Compulsory elective subject & Number & percentile & Number & percentile \\
\hline Industrie 4.0 / Digital Transformation & 6 & $46.2 \%$ & 2 & $15.4 \%$ \\
Process Optimisation / Process Management & 2 & $15.4 \%$ & 4 & $30.8 \%$ \\
Employee and Company Management & 2 & $15.4 \%$ & 1 & $7.7 \%$ \\
IT Service Management* & 1 & $7.7 \%$ & 3 & $23.1 \%$ \\
Project Management & 1 & $7.7 \%$ & 2 & $15.4 \%$ \\
Cloud-Computing / Virtualisation & 1 & $7.7 \%$ & 1 & $7.7 \%$ \\
E-Business* & - & - & - & - \\
\hline$*$ originally intended by the university as an elective subject & & & \\
\hline
\end{tabular}

The ITBM group's test selection underscores a clear preference for those subjects, which were identified by the survey among IT professionals interested in studying. 
Table 9. Interest assessment - Compulsory elective subjects

\begin{tabular}{lllll}
\hline Compulsory elective subject & Mode $(\mathrm{n}=13)$ & Median $(\mathrm{n}=13)$ & $\mathrm{R}(\mathrm{n}=13)$ & $\mathrm{SD}(\mathrm{n}=13)$ \\
\hline Industrie 4.0 / Digital Transformation & 5 & 5 & $1-5$ & 1.08 \\
Cloud-Computing / Virtualisation & 5 & 3 & $1-5$ & 1.33 \\
Process Optimisation / Process Management & 4 & 4 & $4-5$ & 0.50 \\
Employee and Company Management & 4 & 4 & $2-5$ & 0.99 \\
Project Management & 4 & 4 & $2-5$ & 1.07 \\
IT Service Management* & 3 & 3 & $2-5$ & 0.92 \\
IT Security & 3 & 3 & $1-5$ & 1.19 \\
E-Business* & 3 & 3 & $1-5$ & 1.20 \\
\hline * originally planned elective module & & & \\
Legend: I find it uninteresting (1), I find it rather uninteresting (2), & & & \\
neither nor (3), I find it rather interesting (4), I find it interesting (5) & &
\end{tabular}

When assessing the specialisation topics in terms of interest, those topics with a focus on future requirements revealed the greatest level of interest during the first survey.

The results of the surveys suggest that only those surveys and interviews on future requirements identified topics that are much more closely aligned with the requirements of students studying on an extra-occupational basis. From the data, various study modules were developed for the different qualification levels of the study programmes on offer in the "Open IT" project.

\section{Impact of the Results on the Design Process for Study Modules}

The elective modules developed were subdivided in the following for the respective levels into the disciplines of "Management" and "Informatics". In terms of study content, the university conducted a pre-selection, in order to account for the students' preferences and to give due consideration to those specialisation offers which, while not in line with students' preferences, should be offered to ensure the availability of a solid foundation offering.

\subsection{Elective Modules "Management" (Bachelor Level)}

In this area, despite the focus on Industry 4.0, changes were made in order to accommodate students from smaller companies. This term is now the subject of further development by focusing on digitalisation and digital transformation. This should also take greater account of the processing of information, as predicted by the "informatisation" approach. Information processing will play an increasingly important role in the area of Industry 4.0 and, in particular, in the digital transformation of business models (Hanschke, 2018). By opening up the concept, the university hopes to acquire a deeper understanding of subsequent elective modules in Informatics that will take place in the areas of "Business Intelligence", "Data Warehouse" and "Data Mining". Another focus in the discipline of digitalisation courses will be on the topic of "New Work" (Giesen \& Kersten, 2018) or the desired topic of "Work 4.0".

\subsubsection{Course Contents "Digitalisation I \& II"}

The teaching module "Digitalisation I: Digital Transformation and Economics" (von Zobeltitz, 2018a) teaches the basics of digital transformation with certain specialisations. After completing the module, students should be in a position to understand and discuss digital transformation in the business world. For this purpose, a fundamental understanding of digital transformation and the mechanisms of digital transformation in the economy, in companies and in business models is imparted and tested using practical examples. In order to sharpen students's knowledge, the module also includes teaching a foundation understanding of production in the context of "Industry 4.0", the associated decentralised and distributed production as well as the logic of related business models. The course "Digitalisation I" will take place at the extra-curricular learning location known as the Coworking and Maker Space 'Hafven' in Hanover, in order to ensure the course's close proximity to practice and to provide insight into existing innovative concepts. Building on the module "Digitalisation I: Digital Transformation and Economics" the module "Digitalisation II: Working and learning in a changing world" (von Zobeltitz, 2018b) was also created. During this module, students should become acquainted with (and be able to abstract and combine) reflexive skills in the disciplines of the changing world of work, digitalisation and competency development within the company environment. Following on from the terms "Work 4.0" and "Learning 4.0", the relationship between subject, organisation and technology is reflected in a theory-based way. Students should be empowered to develop a critical perspective on the design of learning and communication processes in the context of digitalisation. By combining these modules, students should learn to deal with the 
challenges placed on Management in a digital world, and to support innovation in personal work environments.

\subsubsection{Elective Module: "IT Security" \& "IT Law"}

This elective module consists of the modules "IT Security" (Bühse, 2018) and "IT Law" (Heinze, 2018). As part of the "IT Security" module, students are prepared to undertake the role of Data Protection Officer (DPO) in companies, or to actively support the Company Audit function during a compliance audit with regard to the legal requirements for data protection and information security. The module covers in detail the legislation stemming from the field of information security, including the laws pertaining to Antitrust, the Criminal Code, the Federal Office for Information Security, the Telecommunications Act, the Telemedia Act, the Freedom of Information Act and the Federal Data Protection Act. The main focus of the module is on the operational application of the Data Protection Act and should help sensitise IT professionals to the importance and implementation of data protection. As part of the "IT Law" module, students learn about the legal framework of IT law. In particular, aspects of liability, domain law, the basics of e-commerce and the special features of B2C business are considered on a case-by-case basis. This also includes the fundamental principles of competition and data protection with regard to the collection, storage and use of customer data. The aim of the modules mentioned here is to deal with legal and information security topics in a digital world and thus to be able to offer an ideal alternative to the management-oriented elective module of "Digitalisation". In this way, students should be granted different perspectives on digital work.

\subsection{Elective Modules "Informatics" (Bachelor Level)}

With the elective modules in the discipline of "Informatics" students will, among other things, have the choice of "Cyber Security I \& II" and "Business Intelligence". It is still unclear at this time as to whether the module "Cloud Computing" is also to be developed for Bachelor students, or whether it should remain exclusively for the Master's programme. "Cyber Security I \& II" will cover the following topic areas: Operating systems, the foundations of cyber security in the context of business and software security, the basics of malware and hacking, legal, compliance and ethical issues, as well as the requirements placed on operational and general cyber security management. Operational security management includes the creation of IT security infrastructure and architecture as well as physical security systems, cryptography and encryption techniques. Under general "Cyber Security Management" the facilitation of a management perspective shifts to IT systems, taking into account certifications, strategic IT risk management and the associated necessary administrative processes within the company.

Within the discipline of "Cloud Computing", a course is currently being developed (as of September 2018) focusing on the simulation and administration (Moravic, Uramova, Segec \& Kontsek, 2017) of Cloud offerings as well as the targeted adaptation and development of Cloud services (Leelavathy, Sowmya \& Sushmitha, 2018).

In addition to the aspects listed here, the specialisation offers of "Business Intelligence" and "Software Engineering" are also being developed. The specialisation "Business Intelligence" focusses on the topics of "Data Warehouse" and "Data Mining". "Software Engineering" is offered to deliver an understanding of fundamental IT principles. These study programmes will be offered to students in the winter semester 2018/2019 in order to assess whether the modules identified in the surveys are actually preferred during the final and binding election of modules.

\subsection{Elective Subjects "Management" (Master Level)}

In addition to the development of compulsory elective subjects for the Master's programme, based on the survey results the curriculum for the certificated "Master of IT Business Management" has been adjusted.

For example, the subject of "Digitalisation" will be offered to all students in this certificated study programme and will replace the "Marketing" study module planned to date for the first semester of the Master's degree programme. This was due to the preference for the topic area of "Digital Transformation" identified in the surveys. The course "Digitalisation" is currently being evaluated to determine the degree to which an extension of the theory, based on the principles of computerisation, would be prudent, in order to be able to increase the content to the necessary Master's level. Consideration is also being given to how content from the previously presented modules of the Bachelor's study programme could be integrated. In addition, the "Cyber Security I" module was included in the curriculum as a basis, replacing the previous Business Administration module "Controlling and Risk Management". Here too, the wish for a stronger IT orientation in the curriculum should be taken into account.

With the specialisation subjects in the Master's study programmethe offer for students is extended given that it remains questionable as to how they foresee their professional future after the certificated study course 
"Bachelor in IT Business Management". The Management-oriented specialisation subjects of "Personnel and Corporate Management" and the removal of "Marketing" as a core offering, as well as the IT-oriented specialisations of "Cloud Computing", "Data Mining" and "Cyber Security II" are planned as a specialisation for the previous course "Cyber Security". The number of modules then depends on student preferences.

\subsection{Perception of Students}

During the module elections to date, students have shown similar behavior as was witnessed during the preliminary investigations. As of mid-year 2018, only election behavior in relation to courses in the discipline of "Management" at Bachelor level in the group BI could be examined. In this group, the number of participants has been reduced from 19 to 14 persons $(\mathrm{n}=14)$. Nine participants $(64.2 \%)$ opted for the "Digitalisation I \& II" and five participants $(35.8 \%)$ for the "IT Security \& IT Law" specialisation during the selection process. The percentile distribution was almost reversed vis-a-vis the trial elections. Here, $63.2 \%$ of respondents had chosen "IT Security \& IT Law" and 36.8\% "Industry 4.0 / Digital Transformation".

In terms of students' professional background, no preferences could be identified in the real elections. The only conspicuous detail was that all individuals who chose "IT Security \& IT Law" are professionally involved in system integration. This current activity is independent of any previous vocational training. Among those who opted for "Digitalisation I \& II", the dominant proportion of individuals from large companies during the test elections could no longer be detected. This may also be due to the shifting in focus from "Industry 4.0 / Digital Transformation" to the general topic of digitalisation.

The module evaluation of the courses "Digitalisation I \& II" and "IT Security \& IT Law" offered as part of the "Management" discipline to the BI group in the certificated Business Informatics study programme delivered comparable results in terms of the assessment of the lecturer and his / her interaction with the group. The specialisation modules had above-average ratings in comparison to other previously completed modules in the certificated course BA in Business Informatics. This can be seen in the evaluation of the practical relevance of the topic for the students, as well as the module in general. The lecturers also rated the participatory motivation of students as above average. According to Vroom's Valence Instrumentality Expectancy Theory (VIE Theory), the individual's purpose for motivated action plays an important role (Vroom, 1964; Hoffmann \& Akbar, 2016). It can thus (at the very least) be assumed that the consequences of action observed in the form of more active participation, a higher level of motivation and an above-average positive evaluation of the modules are due to the increased valence, i.e. the increased attractiveness of the tailor-made courses on offer. As a result, it can be concluded that the continuous integration of students into the development of study programmes is a prudent choice.

\section{Summary and Outlook}

By affording due consideration to the evaluated and extracted ideas for the specialisation subjects in the study programmes on offer, the requirements stipulated by extra-occupational students could be fulfilled more purposefully and in a more practically relevant way. It should be noted here that this concerns a special target group. In this particular case, prospective students were able to be included as they had already completed vocational training and had gained work experience. As a rule, these conditions cannot be found in all university programmes, as the prospective students usually have no relevant professional experience and are therefore hardly in a position to oversee the subject areas.

These requirements placed on the specialisation offers helped to generate specific ideas for future service offerings with a focus on the occupational origin of the participants. The ideas and aspiration do, in part, align with the continuation of the division of labour and an increase in virtual work and services, as foreseen by the phenomenon of computerisation. It also shows that the field of digitalisation can also be of interest to small businesses. In addition, the virtualisation of work also brings to the fore new occupational fields such as "Cyber Security", which is necessary for working with virtual servers, as well as the partial association of "Cloud Computing".

It was noteworthy that there were no requests regarding the general management of IT services or agile development methods such as: DevOps (Kim, Humble, Debois \& Willis, 2017) or Scrum (Sutherland, 2015). This may be due to participants' orientation in the area of system integration and the associated IT administration, or indeed previously existing knowledge.

The approach presented here demonstrates that universities and students can jointly define topics. However, decision-making and interpretative sovereignty must remain with the university. Its task is to provide guidance in the evaluation process and to interpret the results, as these cannot directly identify relevant requirements due to 
the operational nature of work activities. In addition, the educational institution must consolidate students' preferences and incorporate them into a consistent overall curriculum (Niederdrenk, 2011).

An example of what an academic crediting programme could look like has been exemplified here: the foundations are determined by the necessary general requirements of (extra-occupational student) employers and the educational institution itself. Specialisations and potentially individual modules of the core curriculum are determined by the professional and individual preferences of students, and are evaluated in their core topics in cooperation with the students of the university. Further research appears prudent in view of the realisation that collaborative motivation and the evaluation of precisely tailored events revealed itself to be above average. Planned research activities will serve, among other things, to answer the question of whether the observed relationship between the involvement of students in the development of study courses and their motivation to participate in further investigations can be repeated.

\section{Acknowledgments}

The project underlying this document was funded by the Federal Ministry of Education and Research Germany under funding code $16 \mathrm{OH} 21005$. The author is responsible for the content of this publication.

\section{References}

Albrecht, T., \& Ammermüller, A. (2016). Arbeitsmarktprognose 2030. In Bundesministerium für Arbeit und Soziales (Ed.), Werkheft 02 - Wie wir arbeiten (wollen) (30-35). Paderborn: Bonifatius.

Arndt, V. (2012). Trend: Demographischer Wandel. In DGFP e. V. (Ed.), Megatrends: Zukunftsthemen im Personalmanagement analysieren und bewerten (46-73). Bielefeld: WBV.

$\mathrm{Au}, \mathrm{R}$. (2016). To Cloud Compute, or Not to Cloud Compute?. Innovations in Pharmaceutical Technology, 57, 32-35.

Baukrowitz, A. (2006). Informatisierung und Reorganisation. In A. Baukrowitz, T. Berker, A. Boes, S. Pfeiffer, R. Schmiede \& M. Will-Zocholl (Eds.), Informatisierung der Arbeit - Gesellschaft im Umbruch (98-115). Berlin: Edition Sigma.

Becker, J., \& Häusling, A. (2012). Trend: Technologische Innovationen. In DGFP e. V. (Ed.), Megatrends: Zukunftsthemen im Personalmanagement analysieren und bewerten (94-113). Bielefeld: WBV.

Berger-Grabner, D. (2016). Wissenschaftliches Arbeiten in den Wirtschafts- und Sozialwissenschaften. Wiesbaden: Springer Gabler. https://doi.org/10.1007/978-3-658-13078-7

Boes, A., \& Kämpf, A. (2011). Global verteilte Kopfarbeit - Offshoring und der Wandel der Arbeitsbeziehungen. Berlin: Edition Sigma. https://doi.org/10.5771/9783845269542

Bönick, L., Huck, S., \& von Zobeltitz, A. (2018). Die zeitliche Abfolge und Ausrichtung der ersten Semester für berufsbegleitende Anrechnungsstudiengänge. In M. Städler \& A. von Zobeltitz (Eds.), Akademische Weiterbildung für IT-Fachkräfte (81-92). Hamburg: Schriftenreihe Hochschule Weserbergland.

Bruckner, L., \& Werther, S. (2018) Allgemeiner Überblück über Arbeit 4.0. In S. Werter \& L. Bruckner (Eds.), Arbeit 4.0 aktiv gestalten (15-19). Heidelberg: Springer.

Bühse, J. (2018). Informationssicherheit. Retrieved from www.offene-hochschule.org

Capgemini (2015). Studie IT-Trends 2015. Berlin: Capgemini Deutschland.

Castells, M. (2001). Das Informationszeitalter I - Die Netzwerkgesellschaft. Opladen: Leske + Budrich.

Castells, M. (2003). Das Informationszeitalter III - Jahrtausendwende. Opladen: Leske + Budrich. https://doi.org/10.1007/978-3-322-99676-3

DIHK (2010). IT-Weiterbildung: Rahmenlehrplan mit Lernzielen. Meckenheim: DIHK.

Giesen, R., \& Kersten, J. (2018). Arbeit 4.0 - Arbeitsbeziehungen und Arbeitsrecht in der digitalen Welt. München: C. H. Beck.

Hämmerle, M., Pokorni, B., \& Berthold, M. (2018). Wie Digitalisierung und Industrie 4.0 die Arbeit der Zukunft verändern. In S. Werter \& L. Bruckner (Eds.), Arbeit 4.0 aktiv gestalten (pp. 5-15). Heidelberg: Springer.

Hanschke, I. (2018). Digitalisierung und Industrie 4.0 - einfach und effektiv. München: Carl Hanser. https://doi.org/10.3139/9783446452992

Heinze, F. (2018) IT-Recht. Retrieved from www.offene-hochschule.org

Hoffmann, S., \& Akbar, P. (2016). Konsumentenverhalten. Wiesbaden: Springer Gabler. 
https://doi.org/10.1007/978-3-658-05628-5

Kim, G., Humble, J., Debois, P., \& Willis, J. (2017). Das DevOps Handbuch - Teams, Tools und Infrastrukturen erfolgreich umgestalten. Sebastopol, California: O'Reilly.

Leelavathy, N., Sowmya, C., \& Sushmitha, C. (2018). Standardization in Cloud Computing. Journal of Innovation in Computer Science and Engineering, 5(1), 33-37.

Linke, K., Städler, M., von Zobeltitz, A., \& Blochberger, E. (2017). Motivation of and support from employers concerning the implementation of part-time studies from vocationally trained it worker. eucen Studies Journal of ULLL, I(1), 21-27.

Mayring, P. (2015). Qualitative Inhaltsanalyse - Grundlagen und Techniken. Weinheim: Beltz.

Moravic, M., Uramova, J., Segec, P., \& Kontsek, M. (2017). Teaching cloud computing in cloud computing. 15th International Conference on Emerging eLearning Technologies and Applications. Stary Smokovec. https://doi.org/10.1109/ICETA.2017.8102512

Niederdrenk, K. (2011). Differenzierung der Hochschulen. Köln: Wissenschaftsrat.

Pfeiffer, I., \& Kaiser, S. (2009). Auswirkungen von demographischer Entwicklung auf die berufliche Ausbildung, Bundesministerium für Bildung und Forschung. Berlin: Refarat Grundsatzfragen der beruflichen Bildung.

Pfeiffer, S., \& Suphan A. (2015). Der AV-Index. Lebendiges Arbeitsvermögen und Erfahrung als Ressourcen auf dem Weg zur Industrie 4.0. Working Paper \#1 Finalfassung. Hohenheim: Universität Hohenheim.

Pries, L. (2010). Erwerbsregulierung in einer globalisierten Welt. Wiesbaden: VS. https://doi.org/10.1007/978-3-531-91956-0

Rogalla, I., \& Witt-Schleuer, D. (2004) IT-Weiterbildung mit System. Hannover: Heise.

Speidel, V. (2012). Trend: Globalisierung. In: DGFP e. V. (Ed.): Megatrends: Zukunftsthemen im Personalmanagement analysieren und bewerten (116-128). Bielefeld: WBV.

Städler, M., von Zobeltitz, A., \& Linke, K. (2018). Das Forschungsprojekt "Open IT" und die Bedeutung für IT-PraktikerInnen mit abgeschlossener IT-Erst- und Zweitausbildung. In M. Städler \& A. von Zobeltitz (Eds.), Akademische Weiterbildung für IT-Fachkräfte (3-13). Hamburg: Schriftenreihe Hochschule Weserbergland.

Sutherland, J. (2015). Scrum: The Art of Doing Twice the Work in Half the Time. New York City: Random House Business.

von Zobeltitz, A. (2018a). Digitalisierung I. Retrieved from www.offene-hochschule.org

von Zobeltitz, A. (2018b). Digitalisierung II. Retrieved from www.offene-hochschule.org

von Zobeltitz, A., \& Linke, K. (2018): Anrechnungsstudiengänge - eine Herausforderung für berufsausgebildete PraktikerInnen und Hochschulen?. In M. Städler \& A. von Zobeltitz (Eds.), Akademische Weiterbildung für IT-Fachkräfte (pp. 57-66). Hamburg: Schriftenreihe Hochschule Weserbergland.

Vroom, V. H. (1964). Work and motivation. San Francisco: Jossey-Bass.

Zika, G., Maier, T., Hummel, M., \& Helmrich, R. (2015). Entwicklung von Arbeitskräfteangebot und -bedarf bis 2030 in sechs Regionen. In G. Zika \& T. Maier (Eds.), Qualifikation und Beruf in Deutschlands Regionen bis 2030 (9-68). Bielefeld: WBV.

\section{Copyrights}

Copyright for this article is retained by the author(s), with first publication rights granted to the journal.

This is an open-access article distributed under the terms and conditions of the Creative Commons Attribution license (http://creativecommons.org/licenses/by/3.0/). 